\section{Thrombolysis for acute submassive pulmonary embolism: CON viewpoint}

\author{
A John Simpson
}

The normotensive patient with confirmed pulmonary embolism (PE) and right ventricular (RV) dilatation presents a significant dilemma to clinicians. On one hand, a string of publications have demonstrated that RV dysfunction is associated with adverse outcomes in patients with $\mathrm{PE} ;{ }^{1-5}$ on the other, thrombolysis carries a significant risk of bleeding. ${ }^{6} 7$ However, evidence emerging in recent years has provided a strong case against using thrombolysis in this setting, greatly aiding clinical decision-making in submassive PE (taken here to mean confirmed PE in a normotensive patient with evidence of RV dilatation and/or RV dysfunction and/or pulmonary hypertension). The aim of this article is to review some of the most important data surrounding this debate.

The decision to administer systemic thrombolysis would be easier if submassive PE had a high mortality rate that was significantly reduced by treatment. However, this is not the case. In larger studies, inhospital or 30-day mortality for submassive PE treated without thrombolysis is typically between $1 \%$ and $5 \%,{ }^{3}{ }^{8-11}$ though lower and higher rates have been described. ${ }^{12-14}$ In the excellent, landmark randomised controlled trial (RCT) of thrombolysis versus heparin alone for submassive PE, mortality was $3.4 \%$ in the thrombolysed group and $2.2 \%$ in the 'heparin-alone' group. ${ }^{8}$ The argument is commonly made that trials exclude elderly patients or patients with comorbidities, artificially reducing mortality rates. However, the large RIETE registry also suggests a 90-day mortality of around 3\% in patients with submassive PE. ${ }^{15}$ The problem for advocates of thrombolysis in $\mathrm{PE}$ is that it may be technically impossible to demonstrate beneficial effects on mortality. This is because an RCT comparing

Correspondence to Professor John Simpson, Institute of Cellular Medicine, 4th Floor, William Leech Building, Medical School, Newcastle University, Newcastle upon Tyne NE2 4HH, UK; j.simpson@ncl.ac.uk thrombolysis and standard treatment would require prohibitively large numbers of patients to generate sufficient statistical power to detect a clinically meaningful difference in mortality.

Faced with this problem, those who champion thrombolysis might argue first that RV dilatation (and particularly persistent RV dilatation) ${ }^{16}$ is associated with a poor prognosis in $\mathrm{PE},{ }^{1-5}$ and second that thrombolysis improves RV dynamics acutely. ${ }^{17-20}$ Consequently, they may suggest we should thrombolyse patients who have sufficient thrombus load to generate RV dilatation. Again, however, there is very little evidence in submassive PE to support this contention. A crucial point is that RV dilatation is a dynamic process. A large study indicated that $93 \%$ of patients with submassive PE, treated without thrombolysis, had normal RV systolic pressure (assessed by echocardiography) 6 months after diagnosis. ${ }^{10}$ The same study reported two inpatient deaths among 200 patients with submassive PE. ${ }^{10}$

The emerging picture is that, at the point of presentation, patients with submassive PE are highly likely to survive if treated with heparin alone and that the associated RV dilatation is likely to resolve spontaneously in the significant majority. The nagging doubt, of course, surrounds the small proportion of patients who will have persistent RV dysfunction, particularly as this group seems vulnerable to recurrent venous thromboembolism (VTE). ${ }^{16}$ The decision to give thrombolysis would again be easier if, at the point of presentation, we had tools accurately identifying those patients in whom RV function will fail to improve. However, two problems arise. First, while biomarkers such as brain natriuretic peptide afford some additional information, ${ }^{21-24}$ they do not yet provide anywhere near the level of prognostic accuracy on which to base the decision to thrombolyse. ${ }^{25}$ Second, even if they did, we have no evidence to suggest that early thrombolysis could outperform existing treatment options for these patients. Extending this argument, the two major concerns in patients with persistent RV dysfunction are the higher rate of recurrent VTE in patients with residual thrombus load ${ }^{16} 26$ and the development of chronic thromboembolic pulmonary hypertension $(\mathrm{CTEPH}) .{ }^{27}{ }^{28}$ However attractive it may be theoretically, we have no strong evidence to inform whether early thrombolysis can reduce VTE recurrence-we know that longer-term anticoagulation does. ${ }^{29}$ Similarly, we have no evidence that early thrombolysis reduces the risk of CTEPH, yet modern treatments significantly improve outcomes for this important complication. $^{30} 31$ So, instead of early thrombolysis, why not repeat echocardiography at 3 months, prolong anticoagulation in those with persistent RV impairment and assess carefully for evidence of CTEPH in the ensuing period?

The theoretical argument against this approach might be the hypothesis that thrombolysis improves haemodynamics acutely and that a normally functioning RV might lead to fewer complications downstream. However, careful studies have shown that while thrombolysis improves RV dilatation more than heparin alone in the first $12 \mathrm{~h}$, the benefits are lost by $48 \mathrm{~h}^{20}$ There is no evidence in submassive PE to suggest that the early haemodynamic improvements translate into benefits in terms of survival, VTE recurrence or development of CTEPH. ${ }^{8}$ Where early thrombolysis does seem to benefit patients with submassive PE is in reducing the amount of supportive care (eg, blood pressure support) required in the early stages of admission to hospital. ${ }^{8}$ However, again, at the point of presentation, we have no accurate way to predict which patients will require extra haemodynamic support, and the extra supportive care we can give obviates any excess mortality in patients who do not receive thrombolysis.

The arguments against thrombolysis above would matter less if the risks of bleeding associated with thrombolysis were acceptable. Registry data and data from existing RCTs suggest that in the specific setting of $\mathrm{PE}$, thrombolysis is associated with major bleeding rates of 
10\%-20\%. ${ }^{6} \quad 73233$ The great anxiety with thrombolysis clearly relates to major intracranial haemorrhage $(\mathrm{ICH})$. The large ICOPER registry reported that 3\% of patients receiving thrombolysis for $\mathrm{PE}$ developed $\mathrm{ICH} ;{ }^{6}$ other studies report rates approximating to this value. ${ }^{34}$ We must keep in mind that 30-day mortality in submassive PE (with or without thrombolysis) is around 3\%. Data suggest that the risk of haemorrhage after thrombolysis for PE is greater in older patients and patients with cancer, ${ }^{7}$ precisely the groups known to be at the highest risk of death from PE. ${ }^{15}$ Other interesting evidence suggests that women may be at higher risk for thrombolysis-induced haemorrhage than men, while simultaneously having lesser haemodynamic benefits, ${ }^{33}$ but this requires confirmation.

The arguments presented above are firmly against routine use of thrombolysis in submassive PE. They are in keeping with the conclusions of recent comprehensive international guidelines and meta-analyses which found no evidence to support thrombolysis in this setting. ${ }^{35-37}$ However, in many ways the real question should be whether, as a profession, we improve outcomes for patients when we give thrombolysis in the 'real world'. Perhaps clinical experience and assessment at the bedside drive a beneficial use of thrombolysis that could be undetectable in trials or in strict study protocols? Two recent studies throw light on this issue. Data from the large RIETE registry suggest that we do use thrombolysis to advantage in hypotensive patients with PE. ${ }^{38}$ However, interestingly, thrombolysis was associated with significantly increased mortality (odds ratio 2.32) among normotensive patients with symptomatic acute PE. ${ }^{38}$ A further study from Pennsylvania provided additional interesting insightsnot only did surprisingly few patients with PE receive thrombolysis, but mortality from thrombolysis was significantly increased among patients in whom indications for the treatment were the lowest. ${ }^{39}$ While recognising inherent limitations in retrospective studies, and the fact that the latter study did not specifically analyse submassive PE, the inference seems to be that doctors appear reluctant (perhaps nervous) to give thrombolysis for PE and that inappropriate thrombolysis has important detrimental consequences.

We are left in a difficult and sobering position when faced with a patient with submassive PE. The evidence would suggest that your patient has around a $2 \%-3 \%$ chance of dying in hospital and you are highly unlikely to save his/her life in the acute phase by using thrombolysis. The RV dilatation is highly likely to resolve spontaneously. There is a chance of up to one in five that you will induce significant bleeding with thrombolysis, and a one in 30 chance that you will cause ICH. Results from the important, large and beautifully designed PEITHO trial of thrombolysis for normotensive patients with RV dysfunction have been eagerly awaited in the expectation that they will provide increased clarity in this debate. $^{40}$

The literature currently cannot help with your anxieties that a very small proportion of patients with submassive PE will progress to recurrent VTE or CTEPH, and that at the point of presentation you cannot accurately predict who they will be. However, you at least know that you can monitor patients with submassive PE and that you have effective, proven therapeutic options for preventing recurrent PE and treating CTEPH.

The real problem of course (and part of the reason for having this important debate) is that we have no reliable and accurate tools to pinpoint the important minority of patients with submassive PE who genuinely might benefit from thrombolysis or perhaps from surgical embolectomy. Biomarkers and risk profiling are slowly leading us in the direction of this kind of stratified medicine, and this is a key area for future research. A further, very exciting prospect (as highlighted in the accompanying article (http://dx.doi.org/10.1136/thoraxjnl-2013203413)) is whether low dose thrombolysis can impact on clinically important endpoints in submassive PE without the unacceptable risks of haemorrhage. The recent MOPETT trial offers some real hope in this regard, but will face the exceptionally difficult trial design issues inherent to demonstrating benefits in meaningful clinical endpoints. ${ }^{41}$ In the meantime, the real risks of causing unintentional harm to our patients cast a forbidding shadow over the theoretical benefits of thrombolysis in submassive PE.

Disclaimer The views expressed in this article, and in the accompanying article (http://dx.doi.org/10.1136/ thoraxjnl-2013-203413) do not necessarily represent the personal views or practice of the authors, but have been written to stimulate debate.

Competing interests AJS has received support to attend educational meetings (in the form of travel, accommodation and registration) from GlaxoSmithKline, Astra Zeneca and Boehringer Ingelheim. He has given non-promotional talks for GlaxoSmithKline.

Provenance and peer review Commissioned; internally peer reviewed.
To cite Simpson AJ. Thorax 2014;69:105-107.

Received 1 August 2013

Accepted 6 August 2013

Published Online First 17 September 2013

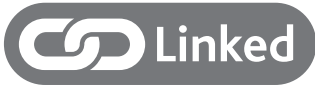

- http://dx.doi.org/10.1136/thoraxjnl-2012-202900

http://dx.doi.org/10.1136/thoraxjnl-2013-203413

http://dx.doi.org/10.1136/thoraxjnl-2013-203746

Thorax 2014:69:105-107.

doi:10.1136/thoraxjnl-2013-204193

\section{REFERENCES}

1 Kasper W, Konstantinides S, Geibel A, et al. Prognostic significance of right ventricular afterload stress detected by echocardiography in patients with clinically suspected pulmonary embolism. Heart 1997;77:346-9.

2 Ribeiro $A$, Lindmarker $P$, Juhlin-Dannfelt $A$, et al. Echocardiography Doppler in pulmonary embolism: right ventricular dysfunction as a predictor of mortality rate. Am Heart J 1997;134:479-87.

3 Grifoni S, Olivotto I, Cecchini P, et al. Short-term clinical outcome of patients with acute pulmonary embolism, normal blood pressure, and echocardiographic right ventricular dysfunction. Circulation 2000;101:2817-22.

4 Quiroz R, Kucher N, Schoepf UJ, et al. Right ventricular enlargement on chest computed tomography: prognostic role in acute pulmonary embolism. Circulation 2004;109:2401-4.

5 Schoepf UJ, Kucher N, Kipfmueller F, et al. Right ventricular enlargement on chest computed tomography: a predictor of early death in acute pulmonary embolism. Circulation 2004; 110:3276-80.

6 Goldhaber SZ, Visani L, De Rosa M, for ICOPER. Acute pulmonary embolism: clinical outcomes in the International Cooperative Pulmonary Embolism Registry. Lancet 1999;353:1386-9.

7 Mikkola KM, Patel SR, Parker JA, et al. Increasing age is a major risk factor for hemorrhagic complications after pulmonary embolism thrombolysis. Am Heart J 1997;134:69-72.

8 Konstantinides S, Geibel A, Heusel G, et al. Heparin plus alteplase compared with heparin alone in patients with submassive pulmonary embolism. N Engl J Med 2002:347:1142-50.

9 Becattini C, Agnelli G, Salvi A, et al. Bolus tenecteplase for right ventricle dysfunction in hemodynamically stable patients with pulmonary embolism. Thromb Res 2010;125:e82-6.

10 Kline JA, Steuerwald MT, Marchick MR, et al. Prospective evaluation of right ventricular function and functional status 6 months after acute submassive pulmonary embolism. Chest 2009:136:1202-10.

11 Jiminez D, Lobo JL, Monreal M, et al. Prognostic significance of mutidetector $\mathrm{CT}$ in normotensive patients with pulmonary embolism: results of the PROTECT study. Thorax 2014;69:109-15.

12 Hamel E, Pacouret G, Vincentelli D, et al. Thrombolysis or heparin therapy in massive pulmonary embolism with right ventricular dilation. Chest 2001:120:120-5

13 Stein PD, Beemath A, Matta F, et al. Enlarged ventricle without shock in acute pulmonary embolism: prognosis. Am J Med 2008;121:34-42.

14 Kostrubiec M, Pruszczyk P, Bochowicz A, et al. Biomarker-based risk assessment model in acute pulmonary embolism. Eur Heart J 2005;26: 2166-72. 
15 Laporte S, Mismetti P, Décousus H, et al. Clinical predictors for fatal pulmonary embolism in 15520 patients with venous thromboembolism: findings from the Registro Informatizado de la Enfermedad TromboEmbolica venosa (RIETE) Registry. Circulation 2008;117:1711-16.

16 Grifoni S, Vanni S, Magazzini S, et al. Association of persistent right ventricular dysfunction at hospital discharge after acute pulmonary embolism with recurrent thromboembolic events. Arch Intern Med 2006;166:2151-6.

17 Miller GAH, Sutton GC, Kerr IH, et al. Comparison of streptokinase and heparin in treatment of isolated acute massive pulmonary embolism. BMJ 1971;2:681-4.

18 Dalla-Volta S, Palla A, Santolicandro A, et al. PAIMS 2: alteplase combined with heparin versus heparin in the treatment of acute pulmonary embolism. Plasminogen Activator Italian Multicenter Study 2. J Am Coll Cardiol 1992;20:520-6.

19 Goldhaber SZ, Haire WD, Feldstein ML, et al. Alteplase versus heparin in acute pulmonary embolism: randomised trial assessing right-ventricular function and pulmonary perfusion. Lancet 1993:341:507-11.

20 Konstantinides S, Tiede N, Geibel A, et al. Comparison of alteplase versus heparin for resolution of major pulmonary embolism. Am J Cardiol 1998;82:966-70.

21 Ten Wolde M, Tulevski II, Mulder JWM, et al. Brain natriuretic peptide as a predictor of adverse outcome in patients with pulmonary embolism. Circulation 2003;107:2082-4.

22 Pieralli F, Olivotto I, Vanni S, et al. Usefulness of bedside testing of brain natriuretic peptide to identify right ventricular dysfunction and outcome in normotensive patients with acute pulmonary embolism. Am J Cardiol 2006:97:1386-90.

23 Logeart D, Lecuyer L, Thabut $\mathrm{G}$, et al. Biomarker-based strategy for screening right ventricular dysfunction in patients with non-massive pulmonary embolism. Intensive Care Med 2007;33: 286-92.

24 Kline JA, Zeitouni R, Marchick MR, et al. Comparison of 8 biomarkers for prediction of right ventricular hypokinesis 6 months after submassive pulmonary embolism. Am Heart J 2008;156:308-14.

25 Söhne M, Ten Wolde M, Boomsma F, et al. Brain natriuretic peptide in hemodynamically stable acute pulmonary embolism. J Thromb Haemost 2006;4:552-6.

26 Siragusa S, Malato A, Saccullo G, et al. Residual vein thrombosis for assessing duration of anticoagulation after unprovoked deep vein thrombosis of the lower limbs: the extended DACUS study. Am J Hematol 2011;86:914-17.

27 Pengo $\mathrm{V}$, Lensing AWA, Prins $\mathrm{MH}$, et al. Incidence of chronic thromboembolic pulmonary hypertension after pulmonary embolism. $N$ Engl J Med 2004;350:2257-64.

28 Becattini C, Agnelli G, Pesavento R, et al. Incidence of chronic thromboembolic pulmonary hypertension after a first episode of pulmonary embolism. Chest 2006;130:172-5

29 Kearon C, Gent M, Hirsh J, et al. A comparison of three months of anticoagulation with extended anticoagulation for a first episode of idiopathic venous thromboembolism. $N$ Engl J Med 1999:340:901-7

30 Condliffe R, Kiely DG, Gibbs JSR, et al. Improved outcomes in medically and surgically treated chronic thromboembolic pulmonary hypertension. Am J Respir Crit Care Med 2008;177:1122-7.

31 Jenkins D, Mayer E, Screaton N, et al. State-of-theart chronic thromboembolic pulmonary hypertension diagnosis and management. Eur Respir Rev 2012;21:32-9.

32 Meneveau N, Ming LP, Séronde MF, et al. In-hospital and long-term outcome after sub-massive and massive pulmonary embolism submitted to thrombolytic therapy. Eur Heart J 2003;23: 1447-54.
33 Geibel A, Olschewski M, Zehender $\mathrm{M}$, et al. Possible gender-related differences in the risk-to-benefit ratio of thrombolysis for acute submassive pulmonary embolism. Am J Cardiol 2007;99:103-7.

34 Kanter DS, Mikkola KM, Patel SR, et al. Thrombolytic therapy for pulmonary embolism: frequency of intracranial hemorrhage and associated risk factors. Chest 1997;111:1241-5.

35 Kearon C, AkI EA, Comerota AJ, et al. Antithrombotic therapy for VTE disease. Antithrombotic therapy and prevention of thrombosis, 9th ed: American College of Chest Physicians evidence-based clinical practice guidelines. Chest 2012;141(Suppl):e419S-94S.

36 Wan S, Quinlan DJ, Agnelli G, et al. Thrombolysis compared with heparin for the initial treatment of pulmonary embolism: a meta-analysis of the randomized controlled trials. Circulation 2004;110:744-9.

37 Dong BR, Hao Q, Yue J, et al. Thrombolytic therapy for pulmonary embolism. Cochrane Database Syst Rev 2009;3:CD004437.

38 Riera-Mestre A, Jiménez D, Muriel A, et al. Thrombolytic therapy and outcome of patients with an acute symptomatic pulmonary embolism. J Thromb Haemost 2012;10:751-9.

39 Ibrahim SA, Stone RA, Obrosky DS, et al. Thrombolytic therapy and mortality in patients with acute pulmonary embolism. Arch Intern Med 2008; 168:2183-90.

40 The Steering Committee. Single-bolus tenecteplase plus heparin compared with heparin alone for normotensive patients with acute pulmonary embolism who have evidence of right ventricular dysfunction and myocardial injury: rationale and design of the Pulmonary Embolism Thrombolysis (PEITHO) Trial. Am Heart $J$ 2012;163:33-8.e1.

41 Sharifi M, Bay C, Skrocki L, et al. Moderate pulmonary embolism treated with thrombolysis (from the "MOPETT" Trial). Am J Cardiol 2013;111:273-7. 